\title{
Editorial 41
}

\section{Eric Scerri}

The current issue contains just two main articles and three book reviews. First up is Gerald Thomas who works in Canada and who discusses the question of reduction and emergence from the point of view of a chemist. In addition to raising some fascinating issues Thomas provides a wealth of references that will be of interest to authors working in this field.

In general chemistry classes one frequently learns that oxidation and reduction can be defined in terms of either a loss or gain of electrons respectively or in terms of an increase or decrease in the oxidation number of the element in question. In his article Joseph Sima, who has published in this journal before, explores the fact that the two definitions are not equivalent and goes on to suggest ways of treating the subject more satisfactorily.

We close with three reviews of recent books from the 'Asimov of chemistry', George Kauffman. 